\title{
IMPACT OF ALTERING DIETARY OMEG 6 TO OMEGA 3 FATTY ACIDS RATIO ON GROWTH PERFORMANCE, CARCASS COMPOSITION, HEMATO-BIOCHEMICAL PARAMETERS AND ABSORPTIVE CAPACITY OF THE INTESTINE OF NILE TILAPIA
}

\author{
Eldsokey Nassef ${ }^{1 *}$, Elsayed Hegazi ${ }^{1}$, Ahmed Sherif ${ }^{2}$, Mohamed Elshamy², \\ Abdelnasser Bakr'1, Tarek k. Abouzed ${ }^{3}$
}

\begin{abstract}
${ }^{1}$ Nutrition and Clinical Nutrition Department, Faculty of Veterinary Medicine, Kafrelsheikh University, Kafrelsheikh, Egypt, ${ }^{2}$ Agriculture Research Center, Animal Health research Institute, Kafrelsheikh, Egypt, ${ }^{3}$ Biochemistry Department, Faculty of Veterinary Medicine, Kafrelsheikh University, Kafrelsheikh, Egypt.

*Corresponding author, E-mail: dsokeynassef@yahoo.com
\end{abstract}

\begin{abstract}
The present study investigated the influence of altering omega 6 to omega 3 fatty acids (FA) ratio on growth, hemato- biochemical parameters and absorptive capacity of Nile tilapia. One hundred and fifty fingerlings $(25.1 \pm 0.3 \mathrm{~g})$, were assigned into 3 groups (5 replicates each) and fed on iso-caloric and iso-nitrogenous diets. Diets were supplemented with fish and soy oil to create 3 different ratio of omega 6 to omega 3 FA, namely, $0.91,2.85$ and 9.3 parts of omega 6 to 1 part of omega 3 (R1, R3 and R9, respectively). Increasing the ratio from $\mathrm{R} 1$ to $\mathrm{R} 9$ significantly decreased average daily gain and increased feed conversion ratio. Also this alteration decreased ash content in the carcass on the expense of ether extract. Number of erythrocytes, packed cell volume, hemoglobin concentration were significantly increased in fish fed R1. Feeding R9 increased heterophils and decreased lymphocytes as compared with R1 and R3. Fish fed R1 significantly had high serum protein and serum antibacterial activity $(47.6 \%)$ than $R 9(43.5 \%)$ and R3 (44.9\%). Feeding R1 significantly decreased serum triglycerides, cholesterol and creatinine. Feeding R3 and R1 enhanced absorptive capacity of jejunum villi more than the group fed R9. Increasing the ratio of omega 6 to omega 3 FA from R1 to R9 decreased growth performance through decreasing absorptive capacity of jejunum villi. However, Feeding R3 had a positive effect on growth performance and absorptive capacity of the intestine of Nile tilapia.
\end{abstract}

Key words: fish oil; growth performance; intestinal villi; Nile tilapia; soybean oil

\section{Introduction}

Fish oil is the main lipid source used in the formulation of commercial aqua feeds. The continuous little global production of fish oil into 2030 (1), the highly variable cost have forced intensive research activities to evaluate alternative lipid sources (2). Vegetable oils are important lipid sources with low cost and wide availability. To our knowledge, there was scarce information on the assessment impact of altering omega 6 to omega 3 fatty acids (FA) 
ratio on antibacterial activity and absorptive capacity of the intestine of Nile tilapia.

Tilapia is the most common type of fish used in aquaculture where its production reaches to $66.8 \%$ of total aquaculture production (3). Fish meals and oils are essential part of diet composition in tilapia as a source of protein and lipid (2). Dietary lipids are important for regular growth and modulating immune responses in mammals, fish, sea cucumber, and shrimps (4). Because the expansion of aquaculture, it is expected that the requirements of fish meals and oils by the aquaculture sector will increase, but there are troubles of the high cost and limiting availability of fish meals and fish oils $(1 ; 4)$.

We hypothesized that vegetable oils could replace fish oil due to its low cost and wide availability. However, the difference in the ratio of omega 6 to omega 3 FA can impact fish health and disease resistance. Lipids affect on the immune system by influencing the phospholipids of immune cell membranes, membrane-associated signaling molecules (eicosanoids) and receptor sites (5). Many previous studies used fish meal as a protein supplement when evaluating vegetable oils which supplied a certain amount of long chain poly unsaturated fatty acids. This study aimed to investigate the influence of altering omega 6 to omega 3 FA on growth performance, hematological and biochemical parameters, carcass composition and antibacterial activity of Nile tilapia and assessment of the absorptive capacity of duodenum, jejunum and ilium.

\section{Materials and methods}

\section{Fish and experimental design}

One hundred and eighty fingerlings of Nile Tilapia (25.1 $\pm 0.3 \mathrm{~g})$ were purchased from commercial farm in Kafrelsheikh governorate and were acclimatized to tank conditions for 2 weeks. One hundred and fifty apparently healthy fingerlings of homogenous size were selected and randomly distributed into 3 groups (5 replicates each). Each replicate contained 10 fish per tank of 50-L which was equipped with continuous aeriation, inlet and outlet. The procedures have been approved by the Institutional
Aquatic Animal Care and Use Committee, Faculty of Aquatic and Fisheries Sciences, Kafrelsheikh University.

Three experimental diets were supplemented with fish and soy oils to create 3 different ratio of omega 6 to omega 3 FA. The first ratio (R1) was of 0.91 parts of omega 6 to 1 part of omega 3 FA. The second ratio (R3) was of 2.85 parts of omega 6 to 1 part of omega 3 FA. The final ratio (R9) was of 9.3 parts of omega 6 to 1 part of omega 3 FA. The diets were nearly similar in protein and energy (Table 1). The ingredients were ground to pass through a sieve of $1 \mathrm{~mm}$ and mixed for $20 \mathrm{~min}$. the oil was added with the continuous mixing. Distilled water was added to the diets till forming soft dough. The diets were pelleted in a laboratory pellet mill through $2 \mathrm{~mm}$ diameter die. Pellets were dried in an oven at $60^{\circ} \mathrm{C}$ for $2 \mathrm{~h}$ and freshly used. The experimental period lasted for 8 weeks. The fish were fed twice daily at 8.00 and $15.00 \mathrm{~h}$ at a level of $4 \%$ of body weight for 2 weeks; $3.5 \%$ from 3 to 4 weeks then $3 \%$ from 5-8 weeks. Feed refusal was recovered after feeding and dried using oven at $60^{\circ} \mathrm{C}$ for $2 \mathrm{~h}$ then subtracted from the offered feed.

\section{Growth trial}

Growth parameters were determined according to the following equations:

Body weight gain $\left(\mathrm{BWG}, \mathrm{g}\right.$ fish $\left.^{-1}\right)=$ Final BWT - Initial BWT;

Average daily gain $(\mathrm{ADG}, \mathrm{g})=\mathrm{BWG} /$ duration of the experiment (56 days);

Feed intake $\left(\mathrm{FI}, \mathrm{g}\right.$ fish ${ }^{-1}, 56$ days $)=($ offered feed-feed refusal recovered and dried)/no of fish

Feed conversion ratio $(\mathrm{FCR})=\mathrm{FI}(\mathrm{g}) / \mathrm{BWG}$ (g);

Protein efficiency ratio $(\mathrm{PER})=\mathrm{BWG}$ (g)/dry protein intake $(\mathrm{g})$;

Protein retention $(\mathrm{PR}, \%)=($ protein gain, $\mathrm{g} /$ protein intake, $\mathrm{g}) \times 100$

Energy retention $(\mathrm{ER}, \%)=($ energy gain, kcal)/energy intake, kcal) $\times 100$

Chemical analysis of feed and fish

Representative feed samples were ground through $1 \mathrm{~mm}$ screen (Cyclotec, Foss Sweden). The ground samples were analyzed for crude 
protein based on Kjeldahl method and ether extract (Ankom Technology method), according to (6). NFE was calculated according to the following formula: $\mathrm{NFE}=100$ - (moisture + crude protein + ether extract + ash + crude fiber). Lysine, methionine, calcium and available phosphorus were calculated based on feed composition tables in (2).

At the end of the experiment, 3 fish were randomly collected from each replicate; dried in oven at $60^{\circ} \mathrm{C}$ for $48 \mathrm{~h}$. Dry matter and moisture were determined. The dried samples were analyzed for crude protein, ash and ether extract according to (6).

\section{Blood analysis and immune response assay}

At the end of the experiment, pooled blood sample was collected from 5 fish per tank via the caudal vein into heparinized disposal syringe for complete blood count (CBC). Further blood sample without anticoagulant was collected, centrifuged at $3000 \mathrm{rpm}$ for $15 \mathrm{~min}$ to obtain the serum and stored at $-20{ }^{\circ} \mathrm{C}$ for the biochemical analysis. Blood film was prepared according to (7). Differential leukocyte count was calculated according to (8). Hematocrit, erythrocytes, white blood cell (WBCs) and hemoglobin (HB) were examined according to (9). Serum protein and albumin were calorimetrically measure based on $(10,11)$ respectively. Serum globulin was determined by subtracting the concentration of albumin from protein. The activity of alanine amino transaminase (ALT) and aspartate amino transaminase (AST) was determined as previously described (12).

\section{Histopathological analysis}

Intestinal tissue specimen were obtained at the end of experiment to examine absorptive capacity of villi. The samples were immersed in formalin $10 \%$, embedded in paraffin, stained with haematoxylin and eosin ( $\mathrm{H} \& \mathrm{E})$ and documented photographically with a digital camera (DCM 130E/1.3 megapixels, CMOS Software Scopephoto, China) connected to a light microscope (Leica).

\section{Serum antibacterial test}

Serum bactericidal activity was done following the procedure of (13). Equal volumes $(100 \mu \mathrm{l})$ of serum and A. hydrophila bacterial suspension $2 \times 10^{8}$ (CFU) were mixed and incubated at $25^{\circ} \mathrm{C}$ for $1 \mathrm{~h}$. Blank control was made by replacing serum with sterile phosphate buffer saline (PBS). The mixture was then diluted with sterile PBS at a ratio of $1: 10$. The diluted mixture $(100 \mu \mathrm{l})$ was plated on blood agar and incubated at $37^{\circ} \mathrm{C}$ for $24 \mathrm{~h}$. The number of viable bacteria was determined by counting the colonies grown on the agar plates.

\section{Statistical analysis}

Analysis of variance (ANOVA) was done for all data using the SPSS program (14). Duncan's multiple range was used to determine the significant difference among means at $\mathrm{P}<0.05$.

\section{Results}

\section{Growth performance}

As shown in Table 2, the final weight, BWG and ADG were significantly higher in fish fed R1 than those fed R9. But, fish fed R3 had nearly similar growth parameters to fish fed R1. In sum, ADG of fish fed R1 was the greatest followed by R3 then R9, There was no significant difference in feed intake of fish fed either R1 or R3 or R9. But, FCR was significantly improved in fish fed R1 followed by R3 then R9. PER and PR were greater in fish fed R1 than those fed the other diets. In contrast, ER was significantly greater in fish fed R9 followed by R3 then R1.

\section{Body chemical composition}

As illustrated in Table 3, there is no significant differences between different groups in dry matter, moisture and crude protein. Feeding omega 3 FA (R1) significantly increased mineral density in the skeleton as compared to R9. In contrast, feeding R1 decreased fat deposition in the whole body of fish. Whereas, Feeding R3 still had the same effect of R1 on ash and ether extract concentrations. 


\section{Hematological parameters}

As illustrated in Table 4, feeding R1 increased $\mathrm{RBCs}$ count, $\mathrm{Hb}$ concentration and PCV as compared to R3 or R9. Feeding R1, R3 increased WBCs than R9. However feeding R9 increased heterophil but decreased lymphocyte when compared to the other groups, while monocytes, eosinophil and basophil still unchanged among the dietary treatments.

\section{Biochemical analysis}

As shown in Table 5, although the ALT and AST were significantly lower in fish fed R1. The values of further groups were within the acceptable range. The same trend was recorded in creatinine analysis. Serum globulin was markedly high in fish fed R1. Subsequently, it elevated serum protein because the serum albumin was nearly similar among all treatment groups. Serum triglyceride and cholesterol were significantly lesser in fish fed R1 as compared to R9 or R3 groups. No significant difference in cholesterol concentration between R9 and R3 groups was detected. Feeding R1 increased HDL and decreased LDL than the other two groups. On the other hand, fish fed R3 had a higher HDL and a lower LDL than R9 group.

\section{Antibacterial activity}

As shown in Table 6, the result indicated a significant enhancement of the immune status of group fed R1 but differences in other groups were in acceptable range which showed no threat on fish life.

Table 1: Physical and chemical composition (\%) of the diets for Nile tilapia.

\begin{tabular}{lccc}
\hline Items & \multicolumn{3}{c}{ Dietary treatments ${ }^{\mathrm{a}}$} \\
\cline { 2 - 4 } Corn gluten meal & $\mathrm{R} 1$ & $\mathrm{R} 3$ & $\mathrm{R} 9$ \\
\cline { 2 - 4 } Soybean oil & 10 & 10 & 5 \\
Fish oil & 0 & 2.5 & 0 \\
Corn grain & 5 & 2.5 & 30.0 \\
Dehulled soybean meal & 30.0 & 30.0 & 51.6 \\
Monocalcium phosphate & 51.6 & 51.6 & 1.57 \\
Limestone & 1.57 & 1.57 & 0.68 \\
Salt & 0.68 & 0.68 & 0.35 \\
Methionine, DL & 0.35 & 0.35 & 0.2 \\
Premix b & 0.2 & 0.2 & 0.1 \\
Antimycotoxin & 0.1 & 0.1 & 0.2 \\
Vitamin C & 0.2 & 0.2 & 0.1 \\
Binder & 0.1 & 0.1 & 0.2 \\
Chemical composition of dried pelleted diets & 0.2 & 0.2 & 3302 \\
Digestible energy, Kcal/kg c & & & 32.23 \\
Crude protein \% & 3325 & 3313 & 1.73 \\
Lysine \% & 32.23 & 32.23 & 0.75 \\
Methionine \% & 1.73 & 1.73 & 6.93 \\
Crude fat \% & 0.75 & 0.75 & 0.7 \\
Calcium \% & 6.93 & 6.93 & 0.45 \\
Available phosphorus \% & 0.7 & 0.7 & 0.45 \\
\hline
\end{tabular}

${ }^{a}$ Treatments represent the ratio between omega 6 to omega 3 FA in the diet. R1 is a ratio of 0.91 parts of omega 6 to 1 part of omega 3; R3 is a ratio of 2.85 parts of omega 6 to 1 part of omega 3; R9 is a ratio of 9.3 parts of omega 6 to 1 part of omega 3. ${ }^{b}$ Premix: Magnesium 40mg ; Manganese 10mg ; Zinc150mg ; Iron 30mg ; Copper 5mg ; Iodine $5 \mathrm{mg}$; Cobalt 0.005mg ;Selenium 0.1mg; vit A $5500 \mathrm{UI}$; vit D3 1000UI; vit E 50mg ; vit B1 20mg; vit B2 20mg; vit B6 20mg; vit B12 $0.02 \mathrm{mg}$; niacin $100 \mathrm{mg}$; vit K3 $10 \mathrm{mg}$; biotin $0.1 \mathrm{mg}$;folic acid $5 \mathrm{mg}$. ${ }^{\mathrm{c}}$ Calculated according to (2). 
Table 2: Impact of altering omega 6 to omega 3 FA ratio on growth performance and feed utilization

\section{Dietary treatments ${ }^{1}$}

\begin{tabular}{llll}
\hline Items & $\mathrm{R} 1$ & $\mathrm{R} 3$ & $\mathrm{R} 9$ \\
\cline { 2 - 4 } Initial weight & $25.23 \pm 0.18$ & $25.17 \pm 0.03$ & $25.40 \pm 0.10$ \\
Final weight & $54.96 \pm 0.6^{\mathrm{a}}$ & $51.12 \pm 2.84^{\mathrm{ab}}$ & $50.27 \pm 3.1^{\mathrm{b}}$ \\
Body weight gain & $29.3 \pm 0.90^{\mathrm{a}}$ & $25.96 \pm 2.87^{\mathrm{ab}}$ & $24.87 \pm 1.1^{\mathrm{b}}$ \\
Average daily gain & $0.52 \pm 0.02^{\mathrm{a}}$ & $0.47 \pm 0.05^{\mathrm{ab}}$ & $0.44 \pm 0.06^{\mathrm{b}}$ \\
Feed intake & $57.16 \pm 0.72^{\mathrm{b}}$ & $55.2 \pm 1.41$ & $54.4 \pm 1.10$ \\
Feed conversion ratio & $1.95 \pm 0.04^{\mathrm{a}}$ & $2.1 \pm 0.17^{\mathrm{ab}}$ & $2.24 \pm 0.21^{\mathrm{b}}$ \\
Protein efficiency ratio & $1.59 \pm 0.01^{\mathrm{a}}$ & $1.45 \pm 0.12^{\mathrm{b}}$ & $1.42 \mathrm{~b} \pm 0.13$ \\
Protein retention & $25.8 \pm 1.5^{\mathrm{a}}$ & $23.55 \pm 0.1^{\mathrm{b}}$ & $23.19 \pm 1.05^{\mathrm{b}}$ \\
Energy retention & $45.6 \pm 2.28^{\mathrm{c}}$ & $48.78 \pm 0.16^{\mathrm{b}}$ & $50.05 \pm 0.6^{\mathrm{a}}$ \\
\hline
\end{tabular}

Means \pm SE with different letter within the same raw are significantly different at $\mathrm{P}<0.05 .{ }^{1}$ Treatments represent the ratio between omega 6 to omega $3 \mathrm{FA}$ in the diet. R1 is a ratio of 0.91 parts of omega 6 to 1 part of omega 3 ; R3 is a ratio of 2.85 parts of omega 6 to 1 part of omega 3; R9 is a ratio of 9.3 parts of omega 6 to 1 part of omega 3 .

Table 3: Impact of altering omega 6 to omega 3 FA ratio on body chemical composition (on dry matter basis)

\begin{tabular}{lccc}
\hline & \multicolumn{3}{c}{ Dietary treatments ${ }^{1}$} \\
\hline Items & $\mathrm{R} 1$ & $\mathrm{R} 3$ & $\mathrm{R} 9$ \\
\cline { 2 - 4 } Dry matter & $28.37 \pm 0.56$ & $29.01 \pm 0.29$ & $28.97 \pm 0.88$ \\
Moisture & $71.63 \pm 0.58$ & $71.0 \pm 0.29$ & $71.03 \pm 0.88$ \\
Crude protein & $55.73 \pm 0.15$ & $55.7 \pm 1.7$ & $55.9 \pm 0.11$ \\
Ether extract & $21.8 \pm 1.25^{\mathrm{b}}$ & $23.1 \pm 1.1^{\mathrm{a}}$ & $23.8 \pm 0.4^{\mathrm{a}}$ \\
Ash & $19.6 \pm 1.98^{\mathrm{a}}$ & $17.98 \pm 1.9^{\mathrm{b}}$ & $16.46 \pm 0.78^{\mathrm{c}}$ \\
\hline
\end{tabular}

Means $\pm \mathrm{SE}$ with different letter within the same raw are significantly different at $\mathrm{P}<0.05 .{ }^{1}$ Treatments represent the ratio between omega 6 to omega $3 \mathrm{FA}$ in the diet. R1 is a ratio of 0.91 parts of omega 6 to 1 part of omega 3; R3 is a ratio of 2.85 parts of omega 6 to 1 part of omega 3; R9 is a ratio of 9.3 parts of omega 6 to 1 part of omega 3 .

Table 4: Impact of altering omega 6 to omega 3 FA ratio on hematological parameters

\begin{tabular}{lccc}
\hline & \multicolumn{3}{c}{ Dietary treatments $^{1}$} \\
Items & $\mathrm{R} 1$ & $\mathrm{R} 3$ & $\mathrm{R} 9$ \\
\cline { 2 - 4 } RBCS & $2.57 \pm 0.09^{\mathrm{a}}$ & $2.01 \pm 0.08^{\mathrm{b}}$ & $1.88 \pm 0.1^{\mathrm{b}}$ \\
WBCS & $121.9 \pm 0.3^{\mathrm{a}}$ & $119 \pm 0.7^{\mathrm{a}}$ & $116.3 \pm 1.4^{\mathrm{b}}$ \\
Heterophil & $25 \pm 0.6^{\mathrm{b}}$ & $26.3 \pm 0.6^{\mathrm{b}}$ & $30 \pm 0.6^{\mathrm{a}}$ \\
Monocyte & $4.7 \pm 0.3$ & $3.7 \pm 0.9^{\mathrm{b}}$ & $5.3 \pm 0.7$ \\
Lymphocyte & $66.7 \pm 0.3^{\mathrm{a}}$ & $65.7 \pm 1.2^{\mathrm{a}}$ & $60.7 \pm 0.7^{\mathrm{b}}$ \\
Eosinophil & $3.7 \pm 0.3$ & $4.3 \pm 0.6$ & $4 \pm 0.6$ \\
Basophil & $0.3 \pm 0.6^{\mathrm{a}}$ & $0.3 \pm 0.3$ & $0.7 \pm 0.3$ \\
Hb & $8.7 \pm 0.26^{\mathrm{a}}$ & $7.14 \pm 0.14^{\mathrm{b}}$ & $6.66 \pm 0.1^{\mathrm{b}}$ \\
PCV & $26.1 \pm 0.8^{\mathrm{a}}$ & $22.1 \pm 0.4^{\mathrm{b}}$ & $21 \pm 0.03^{\mathrm{b}}$ \\
\hline
\end{tabular}

Means \pm SE with different letter within the same raw are significantly different at $\mathrm{P}<0.05 .{ }^{1}$ Treatments represent the ratio between omega 6 to omega $3 \mathrm{FA}$ in the diet. R1 is a ratio of 0.91 parts of omega 6 to 1 part of omega 3 ; R3 is a ratio of 2.85 parts of omega 6 to 1 part of omega 3; R9 is a ratio of 9.3 parts of omega 6 to 1 part of omega 3 . 
Table 5: Impact of altering omega 6 to omega 3 FA ratio on biochemical parameters and antibacterial activity

\begin{tabular}{lccc}
\hline & \multicolumn{3}{c}{ Dietary treatments 1 } \\
\hline Items & $\mathrm{R} 1$ & $\mathrm{R} 3$ & $\mathrm{R} 9$ \\
ALT $(\mu / \mathrm{l})$ & $34.3 \pm 1.3^{\mathrm{c}}$ & $41.2 \pm 0.8^{\mathrm{b}}$ & $47.3 \pm 0.9^{\mathrm{a}}$ \\
AST $(\mu / \mathrm{l})$ & $106.3 \pm 2.96^{\mathrm{b}}$ & $112.5 \pm 1.3^{\mathrm{b}}$ & $130 \pm 6.4^{\mathrm{a}}$ \\
Creatinine $(\mathrm{mg} / \mathrm{dl})$ & $0.89 \pm 0.05^{\mathrm{c}}$ & $1.47 \pm 0.09^{\mathrm{b}}$ & $1.86 \pm 0.14^{\mathrm{a}}$ \\
Total protein $(\mathrm{g} / \mathrm{dl})$ & $6.6 \pm 0.15^{\mathrm{a}}$ & $5.7 \pm 0.2^{\mathrm{b}}$ & $5.3 \pm 0.09^{\mathrm{b}}$ \\
Albumin $(\mathrm{g} / \mathrm{dl})$ & $4.1 \pm 0.06^{\mathrm{a}}$ & $4.07 \pm 0.02$ & $4 \pm 0.03$ \\
Globulin $(\mathrm{g} / \mathrm{dl})$ & $2.5 \pm 0.15^{\mathrm{a}}$ & $1.6 \pm 0.3^{\mathrm{b}}$ & $1.2 \pm 0.1^{\mathrm{b}}$ \\
Triglycerides (mg/dl) & $149.5 \pm 1.9^{\mathrm{c}}$ & $295.5 \pm 1.45^{\mathrm{b}}$ & $303.3 \pm 2^{\mathrm{a}}$ \\
Cholesterol (mg/dl) & $98.5 \pm 1.6^{\mathrm{b}}$ & $118.2 \pm 0.7^{\mathrm{a}}$ & $123.5 \pm 2.4^{\mathrm{a}}$ \\
HDL (mg/dl) & $56.2 \pm 0.7^{\mathrm{a}}$ & $51.3 \pm 0.9^{\mathrm{b}}$ & $48.6 \pm 0.6^{\mathrm{c}}$ \\
LDL (mg/dl) & $2.87 \pm 0.3^{\mathrm{c}}$ & $11.5 \pm 3.3^{\mathrm{b}}$ & $20 \pm 0.8^{\mathrm{a}}$ \\
Serum antibacterial $(\%)$ & $47.6 \pm 0.6^{\mathrm{a}}$ & $44.9 \pm 0.4^{\mathrm{b}}$ & $43.5 \pm 0.8^{\mathrm{b}}$ \\
\hline
\end{tabular}

Means \pm SE with different letter within the same raw are significantly different at $\mathrm{P}<0.05 .{ }^{1}$ Treatments represent the ratio between omega 6 to omega $3 \mathrm{FA}$ in the diet. R1 is a ratio of 0.91 parts of omega 6 to 1 part of omega 3 ; R3 is a ratio of 2.85 parts of omega 6 to 1 part of omega 3; R9 is a ratio of 9.3 parts of omega 6 to 1 part of omega 3

Table 6: Impact of altering omega 6 to omega 3 FA ratio on mucosal and villi parameters of the intestine

\begin{tabular}{lllllll}
\hline Dietary treatments & \multicolumn{2}{c}{ Duodenum } & \multicolumn{2}{c}{ Jejunum } & \multicolumn{2}{c}{ Ilium } \\
\cline { 2 - 7 } 1 & length & width & length & width & length & width \\
\hline R1 & $541 \pm 33$ & $141 \pm 13$ & $938 \pm 35^{\text {a }}$ & $115 \pm 4^{\mathrm{b}}$ & $570 \pm 37^{\text {a }}$ & $149 \pm 23$ \\
R3 & $510 \pm 30$ & $139 \pm 13$ & $769 \pm 27^{\text {b }}$ & $113 \pm 6^{\text {b }}$ & $187 \pm 23^{\text {b }}$ & $133 \pm 12$ \\
R9 & $539 \pm 31$ & $150 \pm 10$ & $901 \pm 37^{\text {a }}$ & $142 \pm 10^{\text {a }}$ & $405 \pm 23^{\text {c }}$ & $140 \pm 10$ \\
\hline
\end{tabular}

Means \pm SE with different letter within the same column are significantly different at $\mathrm{P}<0.05$. ${ }^{1}$ Treatments represent the ratio between omega 6 to omega $3 \mathrm{FA}$ in the diet. R1 is a ratio of 0.91 parts of omega 6 to 1 part of omega 3; R3 is a ratio of 2.85 parts of omega 6 to 1 part of omega 3; R9 is a ratio of 9.3 parts of omega 6 to 1 part of omega 3

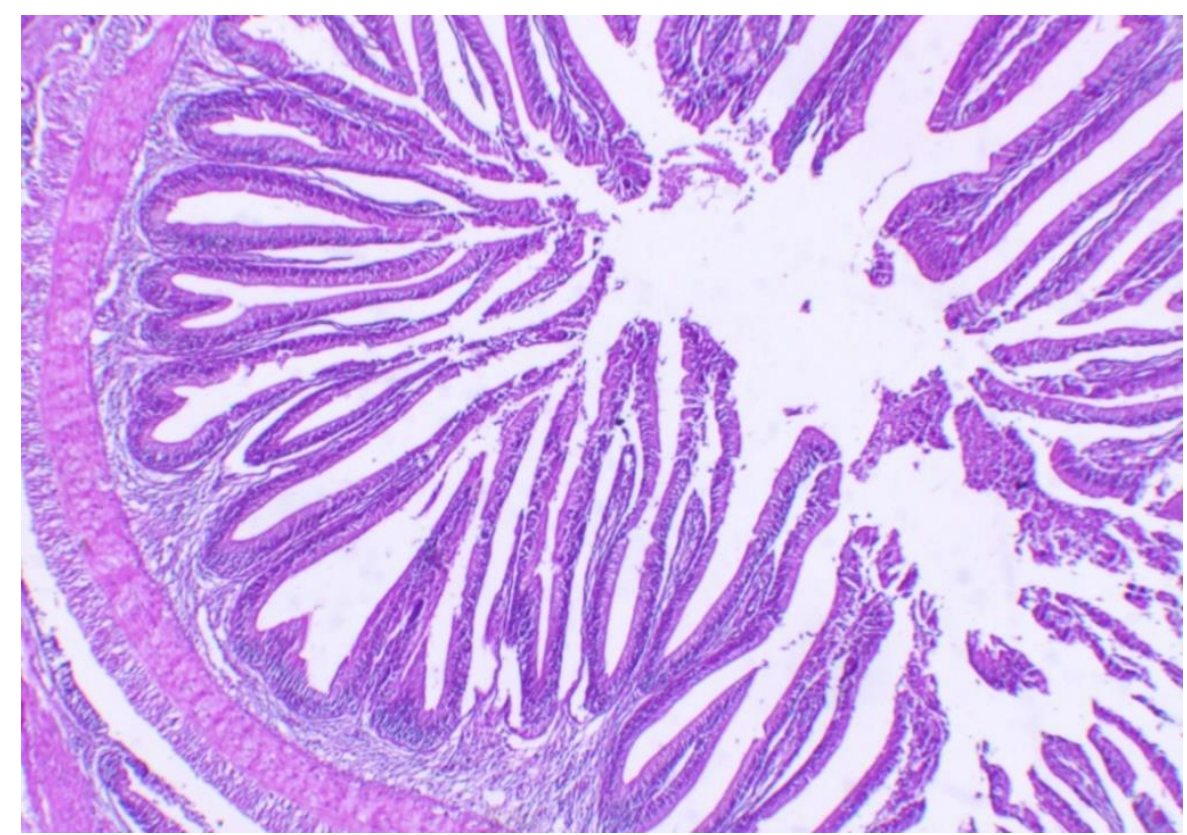

Figure 1: Jejunum of fish supplemented with diet containing fish oil showing normal long villi lined with normal epithelium, (H\&E, X200) 


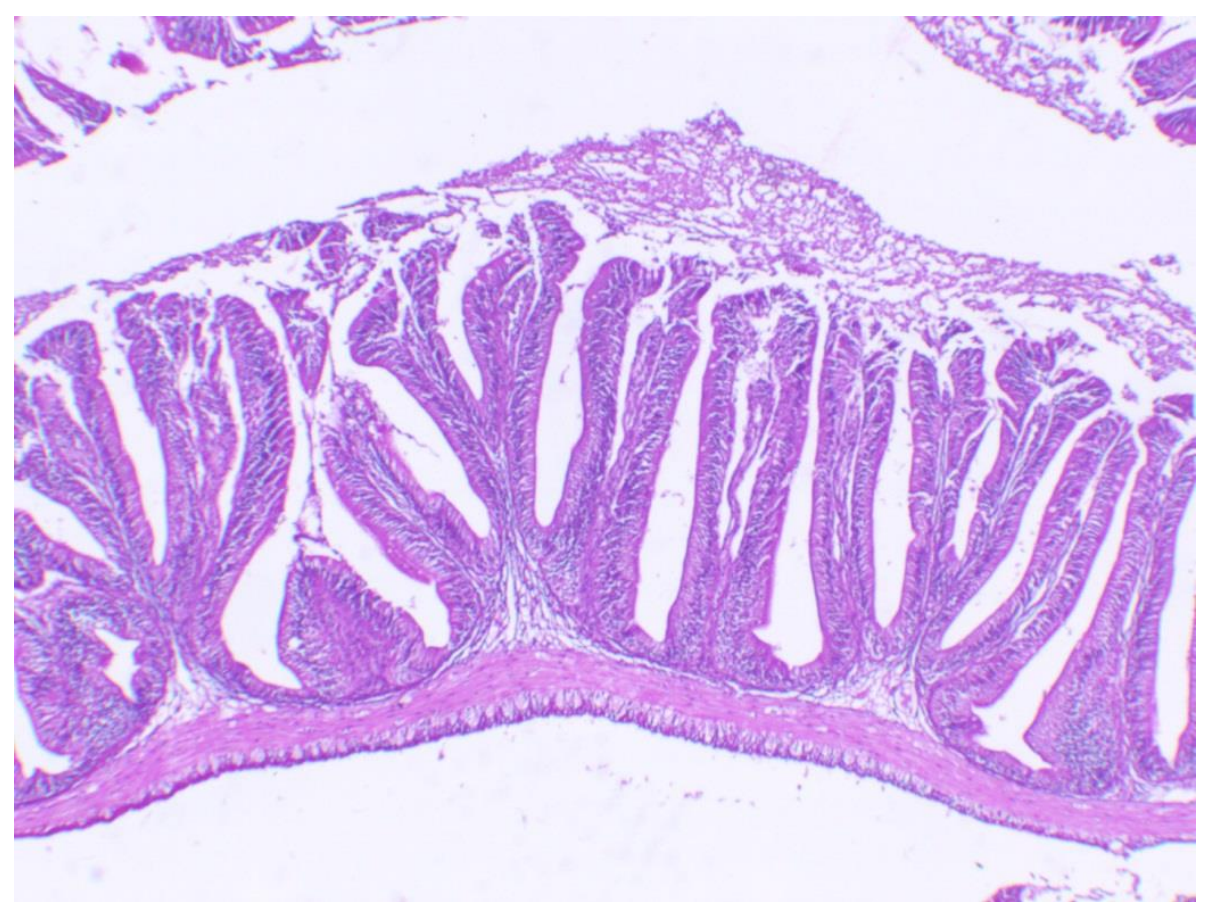

Figure 2: Jejunum of fish supplemented with diet containing vegetable oil showing normal villi, (H\&E, X200)

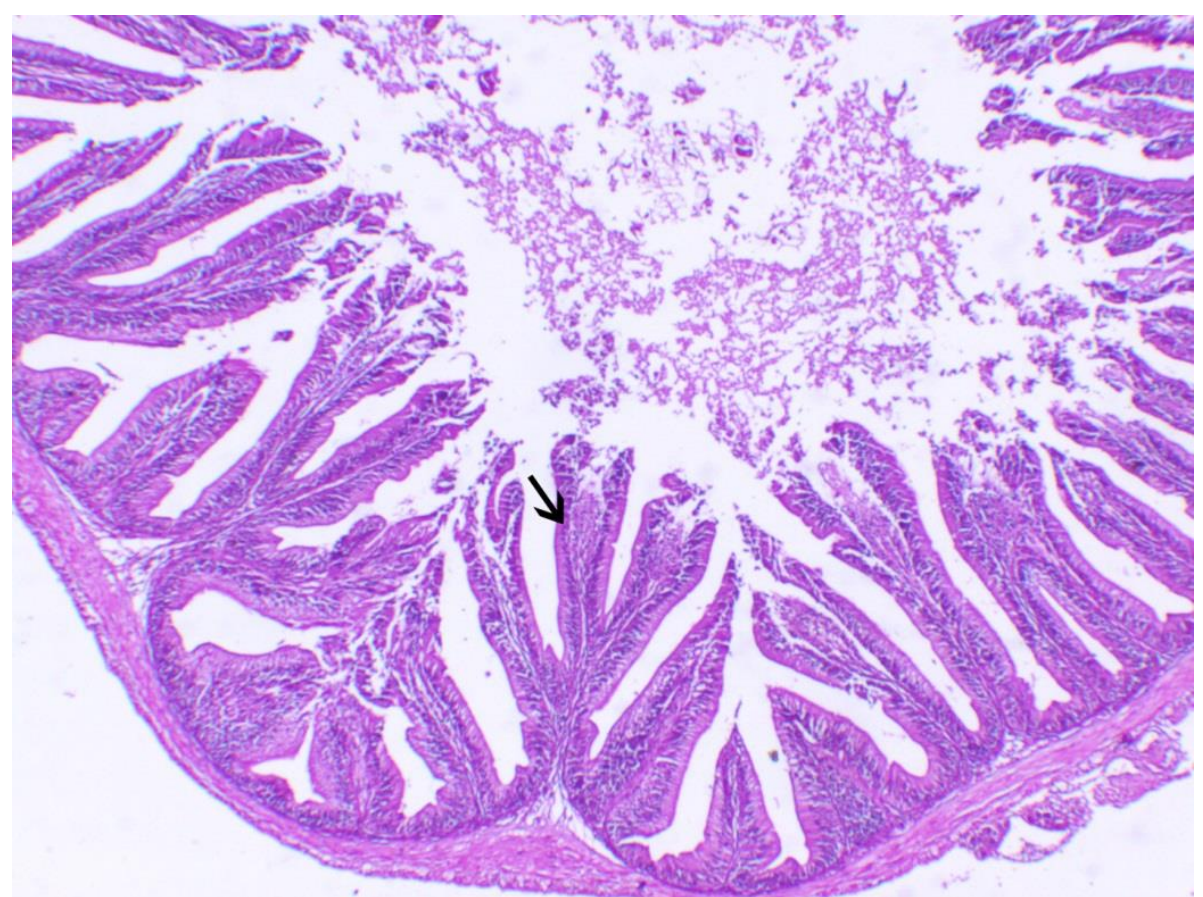

Figure 3: Jejunum of fish supplemented with diet containing a mix of fish and soybean oils showing most of villi length was similar to group 1 with increase branches (arrow), (H\&E,X200)

\section{Histopathological analysis}

Increasing ratio of omega 6 to omega 3 FA from R1 to R9 decreased length of jejunum and ilium villi. Feeding R3 improved the absorptive capacity of intestinal villi as similar to the group fed R1. Jejunum of fish fed R1 showing normal long villi lined with normal epithelium (Fig. 1). Jejunum of fish fed R9 showing normal villi but 
was shorter than the other groups (Fig. 2). Jejunum of fish fed R3 showing most of villi length was similar to fish fed R1 with increase branches and width (Fig. 3). The effect of dietary treatments on duodenum histopathology was not significant (Table 6).

\section{Discussion}

The result of the present study revealed that the fish fed a diet containing a blend of omega 6 and omega 3 FA (R3) had similar BWG to the group fed more omega 3 FA (R1) but higher than that fed omega 6 FA (R9). Similarly, (15) found that the final weight was lower when increasing dietary omega 6 FA by using $6 \%$ soy oil in fish diet for 6 weeks. Also, a recent study denoted that increasing omega 6 to omega $3 \mathrm{FA}$ ratio for 8 weeks depressed growth of tilapia (16). (17) who reported that a moderate increase of omega 6 FA by using $4.5 \%$ SO in replacement of FO in hybrid tilapia diets for 10 weeks, found that all groups had similar final weight. Also, (18) investigated a moderate omega 6 to omega 3 ratio in red hybrid tilapia diets for 5 months and detected no significant difference in either the growth performance or feed efficiency. Some studies have designated that both omega- 3 and omega-6 FAs are indispensable for tilapia (2). These results implied that the presence of moderate dietary levels of omega 6 FA may spare a part of the requirement for omega 3 FA series.

This study revealed that feeding $\mathrm{R} 1$ reduced body fat content. This might be due to the high phospholipid content of fish oil than the soy oil. Lipid rich in omega 3 PUFA is reported to impede the fat synthesis and to reduce the deposition of these FAs in the liver and whole body of fish (19). With regard to phospholipids, (20) found that it decreased total lipids of whole body of rainbow trout as compared to a mixture of olive and linseed oils, also, (21) stated that omega 3 FA decreased lipid concentration in rainbow trout than the omega $6 \mathrm{FA}$. On the other hand, feeding R1 increased mineral deposition in the skeleton. The relation between type of FA and mineral metabolism in fish is less investigated. In some studies on European sea bass, (22) demonstrated that EPA and DHA of marine origin supported vertebral and cephalic growth with less deformities. In terrestrial animals, phospholipid facilitated cartilage mineralization and stimulated insulin like growth factor production which activate bone formation and matrix production. On the other hand, prostaglandins E2 derived from arachidonic acid is a powerful stimulator of bone resorption (23).

These results clarify that feeding R1 improved general health condition of Nile tilapia as indicated by increasing HB concentration, PCV and RBCs count which positively affected the growth performance. Blood cells reflect dietary changes due to their fast renovation (24). Feeding omega 3 FA increases DHA incorporation in cell membrane of erythrocytes which maintains osmotic pressure and nutrient transport across the cell membrane. On the other hand, feeding omega 6 FA to channel catfish increased C18 PUFA and decreased LCPUFA which appeared to increase erythrocyte fragility (25). In another study on salmon, vegetable oils (blend of rapeseed and linseed oils), which are rich in omega 6 FA, decreased erythrocyte counts and hematocrit (26).

Fish fed more omega 3 FA or a mixture of omega 6 and omega 3 FA (R3) had high lymphocyte and low heterophil count than those fed omega 6 FA (R9). However, total count of WBCs was high in fish fed R1 than the other groups. These results differed from the previous reports which documented that omega 3 PUFA inhibit lymphocyte proliferation (27).

The current results revealed that feeding $\mathrm{R} 1$ or R3 enhanced liver function as indicated by lowering serum ALT and AST levels than fish fed R9. This may be due to the associative influence of dietary lipid types on the histological structure of the liver (28). Increasing omega 6 FA in gilt head sea bream diets increased fat accumulation in hepatocyte (29) which subsequently reduced hepatocyte activity leading to metabolic imbalance. Omega 6 FA had a lipogenic effect and lowered oxidation capacity of fish (30). More certainly, feeding omega 6 FA to Atlantic salmon increased molecular expression of adipophilin in the liver (31) which is a marker for lipid accumulation. 
Altering the ratio of omega 6 to omega $3 \mathrm{FA}$ modified immune status (32). Our result of serum antibacterial test indicated that the group fed R1 had significant enhancement of antibacterial activity of fish over the other groups. The use of a moderate omega 6 to omega 3 FA ratio did not alter the health conditions (33).

Results of the histopathology confirmed the beneficial effect of partial replacement of omega 3 with omega 6 FA on absorptive capacity of jejunum villi. Increasing ratio of omega 6 to omega 3 FA from R1 to R9 had a harmful effect on the absorptive capacity of the intestine, subsequently it decreased the growth performance of Nile tilapia fish. To our knowledge, there was scarce information on the effect of altering omega 6 to omega 3 FA ratio on the absorptive capacity of the intestine. Fish oil is rich in omega $3 \mathrm{FA}$ which maintain integrity of cell membrane of the enterocytes which might show the higher length of the jejunum villi than soy oil.

\section{Conclusion}

Increasing the ratio of omega 6 to omega 3 FA from R1 to R9 decreased growth performance and feed utilization of the Nile tilapia. Also, it cleared that feeding more omega 3 and less omega 6 FA was very essential for blood and liver cells. Feeding R9 weakened immune response against bacterial infection and decreased absorptive capacity of jejunum villi. However, it could feed R3 without adverse effect on growth performance, feed utilization and absorptive capacity of the intestine.

\section{Acknowledgments}

The authors would like to thank the stuff members of Feed, Water and Food of animal origin analysis lab, Faculty of Veterinary Medicine, Kafrelsheikh University for their practical provision.

\section{Conflict of interest}

There is no conflict of interest.

\section{References}

1. Food and Agriculture Organization. Fish to 2030 Prospects for Fisheries and Aquaculture.
World bank report number 83177-GLB. December 2013.

2. National Research Council. Nutrient requirements of fish and shrimp. National Academies Press, Washington 2011.

3. El-Adawy M, El-Aziz MA, El-Shazly K, Ali NG, El-Magd MA. Dietary propionic acid enhances antibacterial and immunomodulatory effects of oxytetracycline on Nile tilapia, Oreochromis niloticus. Environmental Science and Pollution Research, DOI: 101007/s11356-018-3206-5 2018.

4. Turchini G, Torstensen B, Ng W. Fish oil replacement in finfish nutrition. Reviews in Aquaculture $2009 ; 1: 10-57$.

5. Montero D, Socorro J, Tort L, Caballero M, Robaina L, Vergara J, Izquierdo M. Glomerulonephritis and immunosuppression associated with dietary essential fatty acid deficiency in gilthead sea bream, Sparus aurata L., juveniles. Journal of Fish Diseases 2004; 27: 297-6.

6. Association of Official Analytical Chemists. Official Method of Analysis 2010; 18th ed. AOAC, Gaithersburg, MD.

7. Lucky Z. Methods for Diagnosis of Fish Disease 1977. Amerind Publishing Co. New York, 1977.

8. Schalm O. Veterinary hematology 1986. Lea and Febiger Philadeiphia. 4th ed.

9. Barros M, Lim C, Klesius P. Effect of soybean meal replacement by cottonseed meal and iron supplementation on growth, immune response and resistance of channel catfish (Ictalurus puctatus) to Edwarsiella ictaluri challenge. Aquaculture 2002; 207: 263-79.

10. Weichselbaum C. An accurate and rapid method for the determination of proteins in small amounts of blood serum and plasma. American journal of clinical pathology 1946; 16: 40-9.

11. Doumas B, Waston W, Biggs H. Albumin standards and the measurements of serum albumin with Bro-mocresol Green. Clinica Chimica Acta 1971; 31: 87-6.

12. Abdelhady D, El-Abasy M, Abou-Asa S, Elbialy Z, Shukry M, Hussein A, Saleh A, El-Magd M. The ameliorative effect of Aspergillus awamori on aflatoxin b1-induced hepatic damage in rabbits. World Mycotoxin Journal 2017;10:363-73.

13. Kajita Y, Sakai M, Atsuta S, Koba-yash M. The immunostimulatory effects of levamisole on rainbow trout, On-corhnchus mykiss. Fish Pathology 1990; 25: 93-8.

14. SPSS. Statistical and package for social science, SPSS for windows release14.0.0, 19 June, 
2004." Standard version, copyright SPSS Inc., 19892004.

15. Szabo A, Mezes M, Hancz C, Molnar T, Varga D, Romvari R, Febel H. Incorporation dynamics of dietary vegetable oil fatty acids into the triacylglycerols and phospholipids of tilapia (Oreochromis niloticus) tissues (fillet, liver, visceral fat and gonads). Aquaculture Nutrition 2011; 17: 13247.

16. Peng X, Li F, Lin S, Chen Y. Effects of total replacement of fish oil on growth performance, lipid metabolism and antioxidant capacity in tilapia (Oreochromis niloticus). Aquaculture International 2016; 24:145-56.

17. Han C, Zheng Q, Feng L. Effects of total replacement of dietary fish oil on growth performance and fatty acid compositions of hybrid tilapia (Orechromis niloticus 9 O.aureus). Aquaculture International 2013; 21:1209-17.

18. Ng W, Chong C, Wang Y, Romano N. Effects of dietary fish and vegetable oils on the growth, tissue fatty acid composition, oxidative stability and vitamin E content of red hybrid tilapia and efficacy of using fish oil finishing diets. Aquaculture 2013; 372-375: 97-110.

19. Ribeiro P, Logato P, Paula D, Costa A, Murgas L, Freitas R Effect of different oils in the diet on lipogenesis and the lipid profile of Nile tilapias. Rev Bras Zootec 2008; 37 (8):1331-7.

20. Rinchard J, Czesny S, Dabrowski K Influence of lipid class and fatty acid deficiency on survival, growth, and fatty acid composition in rainbow trout juveniles. Aquaculture 2007; 264:363-71.

21. Guler M, Yildiz M. Effects of dietary fish oil replacement by cottonseed oil on growth performance and fatty acid composition of rainbow trout (Oncorhynchus mykiss). Turk $J$ Vet Animal Science 2011; 35 (3):157-67.

22. Villeneuve L, Gisbert E, Le Delliou H, Cahu $\mathrm{C}$, ZamboninoInfante J. Intake of high levels of levels of vitamin A and polyunsaturated fatty acids during different developmental periods modifies the expression of morphogenesis genes in European sea bass (Dicentrachus labax). Br J Nutrition 2006; 95 : 677-87.

23. Watkins B, Li Y, Lippman H, Seifert M. Omega-3 polyunsaturated fatty acids and skeletal health. Exp Biol Med 2001; 226:485-97.

24. Caballero M, Izquierdo M, Kjorsvik E, Fernandez A, Rosenlund G Histological alterations in the liver of sea bream, Sparus aurata L., caused by short or long term feeding with vegetable oils: recovery of normal morphology after feeding fish oil as the sole lipid source. J Fish Diseases 2004; 27:531-41.

25. Klinger R, Blazer V, Echevarria C Effects of dietary lipid on the hematology of channel catfish, Ictalurus punctatus. Aquaculture 1996; 147, 22533.

26. Bell J, McGhee F, Campbell P, Sargent J. Rapeseed oil as an alternative to marine fish oil in diets of post-molt Atlantic salmon (Salmo salar): changes in flesh fatty acid composition and effectiveness of subsequent fish oil "wash out." Aquaculture 2003; 218:515-28.

27. Calder P. Polyunsaturated fatty acids and inflammation. Prostaglandins Leukotrienes Essential Fatty Acids 2006; 75: 197-202.

28. Genc E, Yilmaz E, Akyurt I. Effects of dietary fish oil, soy-acid oil, and yellow grease on growth and hepatic lipidosis of hybrid tilapia fry. Israeli J Aquaculture-Bamidgeh 2005; 55: 90-6.

29. Robaina L, Izquierdo M, Moyano F, Socorro J, Vergara J, Montero D. Increase of the dietary $\mathrm{n} 3 / \mathrm{n} 6$ fatty acids ratio and addition of phosphorus improves liver histology alterations induced by feeding diets containing soybean meal in gilthead seabream (Sparus aurata). Aquaculture 1998; 161: 281-93.

30. Menoyo D, Izquierdo M, Robaina, L, Gines R, Lopez-Bote C, Bautista J Adaptation of lipid metabolism, tissue composition and flesh quality in gilthead sea bream (Sparus aurata) to the replacement of dietary fish oil by linseed and soybean oils. Br J Nutrition 2004; 92:41-52.

31. Leaver M, Villeneuve L, Obach A, Jensen L, Bron J, Tocher D, Taggart J. Functional genomics reveals increased cholesterol and highly unsaturated fatty acid biosynthesis after dietary substitution of fish oil with vegetable oils in Atlantic salmon (Salmo salar). BMC Genomics 2008; 9:299. Doi: 10.1186/1471-2164-9-299.

32. Kiron V. Fish immune system and its nutritional modulation for preventive health care. Animal Feed Science Technology 2012; 173:111-33.

33. Mourente G, Good J, Bell J. Partial substitution of fish oil with rapeseed, linseed and olive oils in diets for European sea bass (Dicentrarchus labrax L.): effects on flesh fatty acid composition, plasma prostaglandins E-2 and F-2 alpha, immune function and effectiveness of a fish oil finishing diet. Aquaculture Nutrition 2005, 11:25-40. 